\title{
Postovulatory steroidogenesis after ovulation induced by LH or FSH in hypophysectomized pro-oestrous hamsters*
}

\author{
K. Taya $†$ and G. S. Greenwald \\ Department of Physiology, Ralph L. Smith Research Center, \\ University of Kansas Medical Center, Kansas City, Kansas 66103, U.S.A.
}

\begin{abstract}
Summary. Hamsters hypophysectomized (hypox.) and concurrently injected i.p. with $2.5 \mu \mathrm{g}$ ovine LH or $25 \mu \mathrm{g}$ ovine FSH at 13:00 h on the day of pro-oestrus ovulated the normal complement of ova the next morning (Day 1). At 09:00 h on Day 1, serum levels of progesterone were comparable between sham-hypox. and LHtreated hypox. hamsters. In contrast, there were no differences in serum progesterone between FSH-treated or saline-treated hypox. hamsters; a slight but significant increase in serum progesterone occurred at 15:00 h in the FSH-treated animals and this was continued on Day 2, when values were comparable to those in the LH-treated and sham-hypox. hamsters.

The CL induced by LH or FSH produced significant amounts of progesterone in vitro on Day 1 at 09:00 and 15:00 h. On Day 2, there was a significant increase in production of progesterone by the CL of both groups. Production rates of progesterone by $\mathrm{CL}$ in vitro were the same in the LH- and FSH-treated animals on Days 1 and 2. Therefore, once ovulation has occurred in the hamster the newly developed CL gain the ability to synthesize, store and secrete progesterone independently of pituitary hormones for 2 days, although at a delayed rate after FSH treatment.

The results of incubations of the non-luteal (residual) ovarian tissues showed that large quantities of progesterone (about $7 \mathrm{ng} / \mathrm{mg} / \mathrm{h}$ ) were produced on Day 1 by tissue from FSH-treated animals while that of LH-treated hamsters lost progesterone at the rate of about $1 \mathrm{ng} / \mathrm{mg} / \mathrm{h}$. In saline-treated hypox. hamsters the residual tissue produced large amounts of progesterone and small amounts of oestradiol-17 $\beta$ and testosterone in vitro for at least 2 days after hypox. Little oestradiol-17 $\beta$ was produced by the CL of hamsters treated with LH, FSH or sham-hypox. By Day 2 the CL of all 3 groups produced appreciable amounts of testosterone in vitro, whereas on Day 1 only the CL induced by LH secreted testosterone.
\end{abstract}

\section{Introduction}

Follicle-stimulating hormone (FSH) is effective in inducing ovulation in intact pro-oestrous hamsters (Yang \& Papkoff, 1973) and in pro-oestrous hamsters treated with barbiturates or hypophysectomized shortly before the onset of the critical period (Greenwald, 1971). Following a single injection of FSH after hypophysectomy on Day 4 (pro-oestrus), serum levels of progesterone remain low on Days 1 and 2, whereas hypophysectomized hamsters treated with luteinizing hormone $(\mathrm{LH})$ have high serum levels of progesterone on the same days (Greenwald,

* Reprint requests to: Dr. G. S. Greenwald.

† Permanent address: Laboratory of Veterinary Physiology, Faculty of Agriculture, Tokyo University of Agriculture and Technology, Fuchu, Tokyo 183, Japan. 
1974). However, the corpora lutea (CL) induced by FSH have progesterone concentrations comparable to those in CL induced by LH on Days 1 and 2.

The aim of this study was therefore to compare in vitro the steroidogenesis in the $\mathrm{CL}$ and the non-luteal ovarian tissue after LH or FSH treatment and to correlate serum and tissue concentrations of the steroids.

\section{Materials and Methods}

Golden hamsters (Mesocricetus auratus) were maintained on a $14 \mathrm{~h}$ light:10 h dark schedule with the lights on from 05:00 to 19:00 h. At least 3 consecutive 4-day oestrous cycles were monitored before using the animals. Day 1 was defined as the day of ovulation and Day 4 corresponded to pro-oestrus.

The hamsters were hypophysectomized between 12:00 and 13:00 h on Day 4 by a parapharyngeal approach while under sodium pentobarbitone anaesthesia (Greenwald, 1967). The animals were then immediately given a single i.p. injection of $2.5 \mu \mathrm{g}$ ovine LH (NIH-S18) (Group 3) or $25.0 \mu \mathrm{g}$ ovine FSH (NIH-S10) (Group 4). There were 2 control groups, one of hypophysectomized hamsters injected with saline (Group 2) and the other subjected to sham hypophysectomy (Group 1). The hamsters (8/group) were killed by decapitation at 09:00 or 15:00 h on Days 1 or 2 after hypophysectomy. Trunk blood was saved for determination of progesterone, oestradiol-17 $\beta$ and testosterone. At necropsy the sella turcica was examined with a dissecting microscope for fragments of pituitary and any animals in which any gross remnants were present were rejected.

\section{In-vitro incubations}

Details of the incubation technique were as described by Terranova \& Greenwald (1978) and Terranova, Connor \& Greenwald (1978). Immediately after blood collection, the ovaries were removed and placed in ice-cold saline $(9 \mathrm{~g} \mathrm{NaCl} / \mathrm{l})$ until placed in an incubation vial. All $\mathrm{CL}$ were dissected and cleaned of adhering ovarian tissue. From each animal $5 \mathrm{CL}$ were randomly selected. After weighing, the CL and the residual tissue were placed in $0.4 \mathrm{ml} 95 \%$ ethanol for 'zero' time steroid determinations or in an incubation vial containing $1.0 \mathrm{ml}$ freshly gassed $\left(95 \% \mathrm{O}_{2}+5 \% \mathrm{CO}_{2}\right)$ Krebs-Ringer bicarbonate (KRB) buffer (Umbreit, Burris \& Stauffer, 1953). The tissues were then incubated for $2 \mathrm{~h}$ in KRB at $37^{\circ} \mathrm{C}$ in a shaker bath. At the end of the incubation, the medium was snap frozen in an alcohol-solid $\mathrm{CO}_{2}$ mixture and stored at $-20^{\circ} \mathrm{C}$. The tissues were washed gently with cold saline and stored in $0.4 \mathrm{ml} 95 \%$ ethanol. All tissues were homogenized in $95 \%$ ethanol and stored at $-20^{\circ} \mathrm{C}$ until used for estimations of steroids. The production rate was derived by subtracting the average initial concentrations of steroid/mg tissue at time 'zero' from the sum of the steroid concentrations (pg or $\mathrm{ng}$ steroid/mg tissue) in incubated tissue and its incubation medium. This value was then divided by 2 to yield production rate as $\mathrm{pg}$ or $\mathrm{ng}$ steroid $/ \mathrm{mg}$ tissue $/ \mathrm{h}$.

\section{Steroid assay}

The methods used were those previously described by Terranova \& Greenwald (1978) and Terranova et al. (1978). Serum, incubation media and homogenized tissues were assayed for progesterone, oestradiol-17 $\beta$ and testosterone.

Progesterone. The antiserum was provided by Surve, Barco, Brinckerhoff \& Kirsch (1976); the sensitivity of the assay was $5 \mathrm{pg} /$ tube and the inter- and intra-assay coefficients of variation were $4 \cdot 1$ and $2 \cdot 4 \%$ respectively.

Oestradiol-17 $\beta$. The antiserum was provided by Exley, Johnson \& Dean (1971); the 
sensitivity of the assay was $2 \mathrm{pg} /$ tube and the inter- and intra-assay coefficients of variation were 5.2 and $0.7 \%$ respectively.

Testosterone. The antiserum was provided by Pang \& Johnson (1974); the sensitivity of the assay was $2 \mathrm{pg} /$ tube and the inter- and intra-assay coefficients of variation were 9.6 and $0.8 \%$ respectively. Since this antiserum cross-reacts with $5 \alpha$-dihydrotestosterone $(58 \%)$ and androstenedione $(2 \%)$, the steroid levels are referred to as testosterone-equivalents.

\section{Statistics}

Data were assessed by analysis of variance (Snedecor \& Cochrane, 1967) and Duncan's Multiple Range Test (Steel \& Torrie, 1960). Differences were adjudged significant if $P<0.05$.

\section{Results}

\section{Induction of ovulation in hypophysectomized pro-oestrous hamsters}

A single injection of $2.5 \mu \mathrm{g} \mathrm{LH}$ or $25.0 \mu \mathrm{g}$ FSH induced ovulation the next morning in 70 $74 \%$ of the hypophysectomized animals, and the numbers of ovulations were comparable to those in sham-hypophysectomized hamsters (Table 1).

Table 1. Ovulation in hypophysectomized hamsters on Day 1 after various treatments on Day 4

\begin{tabular}{clcc}
\hline & & $\begin{array}{c}\text { No. ovulating/ } \\
\text { Go. treated (\%) }\end{array}$ & No. of ovulations* \\
\hline 1 & Sham-hypox. + saline & $32 / 32(100)$ & $11.6 \pm 0.4$ \\
2 & Saline & $0 / 33(0)$ & - \\
3 & $2 \cdot 5 \mu \mathrm{g} \mathrm{LH}$ & $32 / 46(69 \cdot 6)$ & $11 \cdot 3 \pm 0.3$ \\
4 & $25 \mu \mathrm{g} \mathrm{FSH}$ & $31 / 42(73.8)$ & $12.0 \pm 0.3$ \\
\hline
\end{tabular}

* Mean \pm s.e.m. for no. of hamsters ovulating.

Tissue weights

As shown in Table 2, CL weight in the 3 groups differed only at 09:00 h on Day 2. At all times the residual ovarian tissue was heavier in Groups 1 and 3 than in Groups 2 and 4.

Table 2. Changes in weight of corpus luteum (CL) and non-luteal ovarian tissue (residual) of hypophysectomized hamsters after various treatments on Day 4 of the cycle

\begin{tabular}{llccccc}
\hline & & \multicolumn{2}{c}{ Day 1 (mg/100 g body wt) } & & \multicolumn{2}{c}{ Day 2 (mg/100 g body wt) } \\
\cline { 7 - 8 } \cline { 6 - 7 } \multicolumn{1}{c}{ Group } & Tissue & $09: 00 \mathrm{~h}$ & $15: 00 \mathrm{~h}$ & & $09: 00 \mathrm{~h}$ & $15: 00 \mathrm{~h}$ \\
\hline \multirow{2}{*}{1 (sham-hypox.) } & CL & $2.8 \pm 0.2$ & $3.4 \pm 0.1$ & & $4.6 \pm 0.2^{*}$ & $4.2 \pm 0.3$ \\
& Residual & $28.7 \pm 1.1 \dagger$ & $29.8 \pm 1.0^{\dagger}$ & & $29.8 \pm 1.0 \dagger$ & $26.6 \pm 0.8 \dagger$ \\
2 (saline) & Residual & $20.8 \pm 0.8$ & $22.8 \pm 0.8$ & & $20.1 \pm 0.8$ & $20.3 \pm 1.0$ \\
3 (LH) & CL & $3.2 \pm 0.1$ & $3.2 \pm 0.2$ & & $3.7 \pm 0.3$ & $4.0 \pm 0.1$ \\
& Residual & $29.4 \pm 1.2 \dagger$ & $26.9 \pm 0.9 \dagger$ & & $24.5 \pm 2.0 \dagger$ & $23.5 \pm 1.0 \dagger$ \\
4 (FSH) & CL & $2.8 \pm 0.1$ & $3.3 \pm 0.1$ & & $3.5 \pm 0.1$ & $3.9 \pm 0.2$ \\
& Residual & $22.3 \pm 1.5$ & $22.6 \pm 1.3$ & & $19.1 \pm 0.5$ & $18.7 \pm 0.6$ \\
\hline
\end{tabular}

Values are mean \pm s.e.m. for 8 hamsters/group.

* Significantly different from corresponding CL values in Groups 3 and $4(P<0.05)$.

† Significantly different from corresponding values in Groups 2 and $4(P<0.05)$. 


\section{Serum steroid concentrations}

The changes in progesterone concentrations are shown in Table 3. Values in Group 3 were lower than those in Group 1 only at 15:00 h on Day 1. Values in Group 4 were lower than those in Groups 1 and 3 but greater than those in Group 2 on Day 1, but comparable to those in Groups 1 and 3 on Day 2. In the sham-hypophysectomized hamsters (Group 1), there was a clear-cut circadian rhythm in peripheral levels of oestradiol-17 $\beta$ on Days 1 and 2 with elevated concentrations in the afternoons (Table 3). Oestradiol-17 $\beta$ concentrations in Groups 2,3 and 4 were lower than those in Group 1 but were not themselves significantly different. Testosterone concentrations were higher in Groups 2 and 3 at 09:00 h on Day 1, and in Group 4 the values at 15:00 h on Day 1 were lower than those in any of the other groups.

Table 3. Serum progesterone, oestradiol-17 $\beta$ and testosterone concentrations in hypophysectomized hamsters after various treatments on Day 4 of the cycle

\begin{tabular}{|c|c|c|c|c|c|c|}
\hline Steroid & $\begin{array}{l}\text { Day } \\
\text { of the } \\
\text { cycle }\end{array}$ & $\begin{array}{c}\text { Time } \\
\text { (h) }\end{array}$ & $\begin{array}{c}\text { Group 1 } \\
\text { (sham-hypox.) }\end{array}$ & $\begin{array}{c}\text { Group } 3 \\
\text { (LH) }\end{array}$ & $\begin{array}{c}\text { Group } 4 \\
\text { (FSH) }\end{array}$ & $\begin{array}{c}\text { Group } 2 \\
\text { (saline) }\end{array}$ \\
\hline \multirow[t]{2}{*}{$\begin{array}{l}\text { Progesterone } \\
(\mathrm{ng} / \mathrm{ml})\end{array}$} & 1 & $\begin{array}{l}09: 00 \\
15: 00\end{array}$ & $\begin{array}{l}6.9 \pm 0.4^{\mathrm{a}} \\
9.0 \pm 0.5^{\mathrm{a}}\end{array}$ & $\begin{array}{l}8.8 \pm 0.4^{a} \\
4.8 \pm 0.4^{b}\end{array}$ & $\begin{array}{l}1 \cdot 1 \pm 0.2^{b} \\
2.3 \pm 0.4^{c}\end{array}$ & $\begin{array}{l}0.4 \pm 0.1^{\mathrm{b}} \\
0.5 \pm 0.1^{\mathrm{d}}\end{array}$ \\
\hline & 2 & $\begin{array}{l}09: 00 \\
15: 00\end{array}$ & $\begin{array}{l}6 \cdot 8 \pm 0.4^{a} \\
6 \cdot 5 \pm 0.4^{a}\end{array}$ & $\begin{array}{l}7.3 \pm 0.3^{\mathrm{a}} \\
5.6 \pm 0.5^{\mathrm{a}}\end{array}$ & $\begin{array}{l}6.7 \pm 0.8^{a} \\
5.7 \pm 0.9^{a}\end{array}$ & $\begin{array}{l}0.5 \pm 0.1^{\mathrm{b}} \\
0.4 \pm 0.1^{\mathrm{b}}\end{array}$ \\
\hline \multirow[t]{2}{*}{$\begin{array}{l}\text { Oestradiol-17 } \beta \\
\quad(\mathrm{pg} / \mathrm{ml})\end{array}$} & 1 & $\begin{array}{l}09: 00 \\
15: 00\end{array}$ & $\begin{array}{l}10 \cdot 7 \pm 1 \cdot 2^{\mathrm{a}} \\
48 \cdot 7 \pm 6 \cdot 1^{\mathrm{a}}\end{array}$ & $\begin{array}{l}26 \cdot 7 \pm 2.4^{b} \\
22 \cdot 3 \pm 2 \cdot 6^{b}\end{array}$ & $\begin{array}{l}25 \cdot 2 \pm 3 \cdot 4^{b} \\
26 \cdot 1 \pm 5 \cdot 6^{b}\end{array}$ & $\begin{array}{l}30 \cdot 0 \pm 2 \cdot 2^{b} \\
20 \cdot 2 \pm 3 \cdot 5^{b}\end{array}$ \\
\hline & 2 & $\begin{array}{l}09: 00 \\
15: 00\end{array}$ & $\begin{array}{l}34 \cdot 5 \pm 4 \cdot 2^{\mathrm{a}} \\
60 \cdot 8 \pm 5 \cdot 2^{\mathrm{a}}\end{array}$ & $\begin{array}{l}12 \cdot 6 \pm 1.2^{\mathrm{b}} \\
12.8 \pm 2 \cdot 0^{\mathrm{b}}\end{array}$ & $\begin{array}{l}12.7 \pm 1.2^{\mathrm{b}} \\
10.3 \pm 1.8^{\mathrm{b}}\end{array}$ & $\begin{array}{l}15 \cdot 5 \pm 1 \cdot 5^{\mathrm{b}} \\
15 \cdot 6 \pm 2 \cdot 7^{\mathrm{b}}\end{array}$ \\
\hline \multirow[t]{2}{*}{$\begin{array}{l}\text { Testosterone } \\
(\mathrm{pg} / \mathrm{ml})\end{array}$} & 1 & $\begin{array}{l}09: 00 \\
15: 00\end{array}$ & $\begin{array}{l}71 \cdot 6 \pm 3 \cdot 6^{a} \\
80 \cdot 2 \pm 2 \cdot 8^{a}\end{array}$ & $\begin{array}{r}101 \cdot 9 \pm 4 \cdot 6^{\mathrm{b}} \\
82 \cdot 3 \pm 4 \cdot 3^{\mathrm{a}}\end{array}$ & $\begin{array}{l}68 \cdot 5 \pm 3 \cdot 9^{\mathrm{a}} \\
58 \cdot 0 \pm 5 \cdot 7^{\mathrm{b}}\end{array}$ & $\begin{array}{r}106 \cdot 7 \pm 3 \cdot 2^{\mathrm{b}} \\
98 \cdot 4 \pm 9 \cdot 3^{\mathrm{a}}\end{array}$ \\
\hline & 2 & $\begin{array}{l}09: 00 \\
15: 00\end{array}$ & $\begin{array}{l}64 \cdot 0 \pm 2 \cdot 3^{\mathrm{a}} \\
90 \cdot 3 \pm 8 \cdot 2^{\mathrm{a}}\end{array}$ & $\begin{array}{l}72 \cdot 7 \pm 6 \cdot 2^{\mathrm{a}} \\
55 \cdot 4 \pm 2 \cdot 9^{\mathrm{b}}\end{array}$ & $\begin{array}{l}65 \cdot 6 \pm 4 \cdot 8^{\mathrm{a}} \\
51 \cdot 7 \pm 5 \cdot 9^{\mathrm{b}}\end{array}$ & $\begin{array}{l}73 \cdot 2 \pm 5 \cdot 5^{a} \\
65 \cdot 1 \pm 12.9^{b}\end{array}$ \\
\hline
\end{tabular}

Values are mean \pm s.e.m. for 8 hamsters/group.

Within rows, values with different superscript letters are significantly different $(P<0.05)$.

Table 4. Initial concentrations of progesterone, oestradiol-17 $\beta$ and testosterone in corpora lutea after various treatments on Day 4 of the hamster cycle

\begin{tabular}{|c|c|c|c|c|c|}
\hline Steroid & $\begin{array}{l}\text { Day } \\
\text { of the } \\
\text { cycle }\end{array}$ & $\begin{array}{l}\text { Time } \\
\text { (h) }\end{array}$ & $\begin{array}{c}\text { Group } 1 \\
\text { (sham-hypox.) }\end{array}$ & $\begin{array}{c}\text { Group } \\
\text { (LH) }\end{array}$ & $\begin{array}{c}\text { Group } 4 \\
\text { (FSH) }\end{array}$ \\
\hline \multirow[t]{2}{*}{$\begin{array}{l}\text { Progesterone } \\
\text { (ng/mg) }\end{array}$} & 1 & $\begin{array}{l}09: 00 \\
15: 00\end{array}$ & $\begin{array}{l}13 \cdot 3 \pm 0.5^{a} \\
20.5 \pm 0.5^{a}\end{array}$ & $\begin{array}{r}8.2 \pm 0.5^{b} \\
11.8 \pm 1 \cdot 5^{b}\end{array}$ & $\begin{array}{l}7.5 \pm 1.0^{b} \\
8.8 \pm 0.7^{b}\end{array}$ \\
\hline & 2 & $\begin{array}{l}09: 00 \\
15: 00\end{array}$ & $\begin{array}{l}28 \cdot 0 \pm 1 \cdot 4^{\mathrm{z}} \\
34 \cdot 1 \pm 2 \cdot 1^{\mathrm{a}}\end{array}$ & $\begin{array}{l}25 \cdot 3 \pm 1 \cdot 6^{\mathrm{a}} \\
20 \cdot 5 \pm 2 \cdot 8^{b}\end{array}$ & $\begin{array}{l}32 \cdot 0 \pm 2.7^{b} \\
27.9 \pm 1 \cdot 1^{\mathrm{a}}\end{array}$ \\
\hline \multirow[t]{2}{*}{$\begin{array}{l}\text { Oestradiol-17 } \\
\quad(\mathrm{pg} / \mathrm{ml})\end{array}$} & 1 & $\begin{array}{l}09: 00 \\
15: 00\end{array}$ & $\begin{array}{r}4 \cdot 5 \pm 1 \cdot 0^{a} \\
32 \cdot 6 \pm 6 \cdot 1^{a}\end{array}$ & $\begin{array}{l}<2 \cdot 1^{b} \\
<2 \cdot 1^{b}\end{array}$ & $\begin{array}{l}<2 \cdot 4^{b} \\
<2 \cdot 0^{b}\end{array}$ \\
\hline & 2 & $\begin{array}{l}09: 00 \\
15: 00\end{array}$ & $\begin{array}{l}13.3 \pm 2.5^{a} \\
33.2 \pm 5.6^{a}\end{array}$ & $\begin{array}{l}<1 \cdot 8^{b} \\
<1 \cdot 7^{b}\end{array}$ & $\begin{array}{l}<1.9^{b} \\
<1.7^{b}\end{array}$ \\
\hline \multirow[t]{2}{*}{$\begin{array}{l}\text { Testosterone } \\
\text { (pg/mg) }\end{array}$} & 1 & $\begin{array}{l}09: 00 \\
15: 00\end{array}$ & $\begin{array}{l}<2 \cdot 4^{a} \\
<2 \cdot 0^{a}\end{array}$ & $\begin{array}{l}13 \cdot 0 \pm 2 \cdot 7^{b} \\
13 \cdot 5 \pm 2 \cdot 1^{b}\end{array}$ & $\begin{array}{l}<2 \cdot 4^{\mathrm{a}} \\
<2 \cdot 0^{\mathrm{a}}\end{array}$ \\
\hline & 2 & $\begin{array}{l}09: 00 \\
15: 00\end{array}$ & $\begin{array}{l}19.9 \pm 1.2^{\mathrm{a}} \\
21.0 \pm 1.8^{\mathrm{a}}\end{array}$ & $\begin{array}{l}11.6 \pm 1.4^{b} \\
14.0 \pm 0.8^{b}\end{array}$ & $\begin{array}{l}5 \cdot 2 \pm 0.9^{c} \\
9 \cdot 0 \pm 1.9^{c}\end{array}$ \\
\hline
\end{tabular}

Values are mean \pm s.e.m. for 8 hamsters/group.

Within rows, values with different superscript letters are significantly different $(P<0.05)$. 


\section{Luteal steroid concentrations}

As shown in Table 4, progesterone concentrations on Day 2 were significantly higher than the Day 1 values in all groups $(P<0.05)$. Values in Groups 3 and 4 differed only on Day 2. Oestradiol-17 $\beta$ concentrations showed a definite circadian rhythm in Group 1 hamsters which correlated with significant increases in serum concentrations of this hormone (Table 3). Concentrations in the other 2 groups were below the sensitivity of the assay. Concentrations of luteal testosterone were higher on Days 1 and 2 in Group 3 hamsters than in those in Group 4.

\section{Concentrations of steroids in the residual ovarian tissue}

Progesterone concentrations decreased significantly $(P<0.05)$ on Day 2 in Groups 1 and 3 but there was no difference for Groups 2 and 4 on the 2 days (Table 5). Oestradiol-17 $\beta$ concentrations were very low in Groups 2, 3 and 4. The concentrations of testosterone showed a circadian rhythm with high afternoon levels in Group 1 but there were no differences in the other 3 groups.

Table 5. Initial concentrations of progesterone, oestradiol-17 $\beta$ and testosterone in the residual ovarian tissue after various treatments on Day 4 of the hamster cycle

\begin{tabular}{|c|c|c|c|c|c|c|}
\hline Steroid & $\begin{array}{l}\text { Day } \\
\text { of the } \\
\text { cycle }\end{array}$ & $\begin{array}{l}\text { Time } \\
\text { (h) }\end{array}$ & $\begin{array}{c}\text { Group 1 } \\
\text { (sham-hypox.) }\end{array}$ & $\begin{array}{l}\text { Group } 3 \\
(\mathrm{LH})\end{array}$ & $\begin{array}{c}\text { Group } 4 \\
\text { (FSH) }\end{array}$ & $\begin{array}{c}\text { Group } 2 \\
\text { (saline) }\end{array}$ \\
\hline \multirow[t]{2}{*}{$\begin{array}{l}\text { Progesterone } \\
\text { (ng/mg) }\end{array}$} & 1 & $\begin{array}{l}09: 00 \\
15: 00\end{array}$ & $\begin{array}{l}14.1 \pm 0.8^{\mathrm{a}} \\
15.4 \pm 0.8^{\mathrm{a}}\end{array}$ & $\begin{array}{l}9.3 \pm 0.6^{b} \\
6.9 \pm 0.4^{b}\end{array}$ & $\begin{array}{l}0.9 \pm 0.2^{c} \\
0.5 \pm 0.1^{c}\end{array}$ & $\begin{array}{l}0.4 \pm 0.04^{c} \\
0.3 \pm 0.1^{c}\end{array}$ \\
\hline & 2 & $\begin{array}{l}09: 00 \\
15: 00 \\
\end{array}$ & $\begin{array}{l}1 \cdot 2 \pm 0.1^{\mathrm{a}} \\
1 \cdot 3 \pm 0.2^{\mathrm{a}} \\
\end{array}$ & $\begin{array}{l}1 \cdot 5 \pm 0 \cdot 3^{\mathrm{a}} \\
1 \cdot 3 \pm 0.2^{\mathrm{a}} \\
\end{array}$ & $\begin{array}{l}1.5 \pm 0.2^{\mathrm{a}} \\
0.9 \pm 0.1^{\mathrm{a}} \\
\end{array}$ & $\begin{array}{l}0.2 \pm 0.01^{\mathrm{b}} \\
0.2 \pm 0.03^{\mathrm{b}} \\
\end{array}$ \\
\hline \multirow[t]{2}{*}{$\begin{array}{l}\text { Oestradiol-173 } \\
(\mathrm{pg} / \mathrm{mg})\end{array}$} & 1 & $\begin{array}{l}09: 00 \\
15: 00\end{array}$ & $\begin{array}{l}31 \cdot 3 \pm 4 \cdot 9^{\mathrm{a}} \\
35 \cdot 0 \pm 5 \cdot 1^{\mathrm{a}}\end{array}$ & $\begin{array}{l}0.8 \pm 0.1^{b} \\
0.5 \pm 0.1^{b}\end{array}$ & $\begin{array}{l}3.0 \pm 0.5^{b} \\
1.4 \pm 0.2^{b}\end{array}$ & $\begin{array}{l}2.5 \pm 0.4^{\mathrm{b}} \\
1.0 \pm 0.1^{\mathrm{b}}\end{array}$ \\
\hline & 2 & $\begin{array}{l}09: 00 \\
15: 00 \\
\end{array}$ & $\begin{array}{l}40 \cdot 7 \pm 6 \cdot 9^{\mathrm{a}} \\
60 \cdot 7 \pm 7 \cdot 2^{\mathrm{a}}\end{array}$ & $\begin{array}{c}0 \cdot 4 \pm 0 \cdot 1^{\mathrm{b}} \\
<0 \cdot 3^{\mathrm{b}}\end{array}$ & $\begin{array}{l}0.8 \pm 0.1^{\mathrm{b}} \\
1.3 \pm 0.2^{\mathrm{b}}\end{array}$ & $\begin{array}{l}0.6 \pm 0.1^{\mathrm{b}} \\
1.0 \pm 0.1^{\mathrm{b}}\end{array}$ \\
\hline \multirow[t]{2}{*}{$\begin{array}{l}\text { Testosterone } \\
\text { (pg/mg) }\end{array}$} & 1 & $\begin{array}{l}09: 00 \\
15: 00\end{array}$ & $\begin{array}{r}2 \cdot 2 \pm 0 \cdot 6^{\mathrm{a}} \\
17 \cdot 3 \pm 3 \cdot 0^{\mathrm{a}}\end{array}$ & $\begin{array}{l}3 \cdot 9 \pm 0.1^{b} \\
3 \cdot 5 \pm 0 \cdot 3^{b}\end{array}$ & $\begin{array}{l}<0 \cdot 3^{c} \\
<0.3^{c}\end{array}$ & $\begin{array}{l}2 \cdot 7 \pm 0 \cdot 3^{\mathrm{a}} \\
2 \cdot 3 \pm 0 \cdot 1^{\mathrm{d}}\end{array}$ \\
\hline & 2 & $\begin{array}{l}09: 00 \\
15: 00\end{array}$ & $\begin{array}{r}7 \cdot 0 \pm 0 \cdot 8^{\mathrm{a}} \\
12 \cdot 2 \pm 2 \cdot 2^{\mathrm{a}}\end{array}$ & $\begin{array}{l}2 \cdot 0 \pm 0 \cdot 3^{\mathrm{b}} \\
2 \cdot 4 \pm 0 \cdot 3^{\mathrm{b}}\end{array}$ & $\begin{array}{l}<0.4^{\mathrm{c}} \\
<0.4^{\mathrm{c}}\end{array}$ & $\begin{array}{l}1.5 \pm 0.2^{b} \\
1.8 \pm 0.3^{b}\end{array}$ \\
\hline
\end{tabular}

Values are mean \pm s.e.m. for 8 hamsters/group.

Within rows, values with different superscript letters are significantly different $(P<0.05)$.

Table 6. Production rates of progesterone and testosterone by corpora lutea from hamsters after various treatments on Day 4 of the cycle

\begin{tabular}{|c|c|c|c|c|c|}
\hline Steroid & $\begin{array}{l}\text { Day } \\
\text { of the } \\
\text { cycle }\end{array}$ & $\begin{array}{c}\text { Time } \\
\text { (h) }\end{array}$ & $\begin{array}{c}\text { Group } 1 \\
\text { (sham-hypox.) }\end{array}$ & $\begin{array}{c}\text { Group } 3 \\
\text { (LH) }\end{array}$ & $\begin{array}{c}\text { Group } 4 \\
\text { (FSH) }\end{array}$ \\
\hline \multirow[t]{2}{*}{$\begin{array}{r}\text { Progesterone } \\
\text { (ng/mg/h) }\end{array}$} & 1 & $\begin{array}{l}09: 00 \\
15: 00\end{array}$ & $\begin{array}{l}0.7 \pm 0.6^{\mathrm{a}} \\
6.1 \pm 1.8^{\mathrm{a}}\end{array}$ & $\begin{array}{r}4 \cdot 6 \pm 1 \cdot 2^{b} \\
13 \cdot 2 \pm 1 \cdot 8^{b}\end{array}$ & $\begin{array}{l}10.8 \pm 2 \cdot 6^{b} \\
15 \cdot 2 \pm 2 \cdot 1^{b}\end{array}$ \\
\hline & 2 & $\begin{array}{l}09: 00 \\
15: 00\end{array}$ & $\begin{array}{l}25 \cdot 3 \pm 2 \cdot 1^{\mathrm{a}} \\
24 \cdot 9 \pm 2 \cdot 2^{\mathrm{a}}\end{array}$ & $\begin{array}{l}22 \cdot 6 \pm 2 \cdot 9^{a} \\
23 \cdot 1 \pm 4 \cdot 8^{a}\end{array}$ & $\begin{array}{l}18.7 \pm 2.7^{a} \\
24.6 \pm 4.8^{a}\end{array}$ \\
\hline \multirow[t]{2}{*}{$\begin{array}{r}\text { Testosterone } \\
(\mathrm{pg} / \mathrm{mg} / \mathrm{h})\end{array}$} & 1 & $\begin{array}{l}09: 00 \\
15: 00\end{array}$ & $\begin{array}{l}<1 \cdot 2^{\mathrm{a}} \\
<1 \cdot 0^{\mathrm{a}}\end{array}$ & $\begin{array}{l}2.7 \pm 0.6^{b} \\
9.6 \pm 1.3^{b}\end{array}$ & $\begin{array}{l}<1 \cdot 2^{\mathrm{a}} \\
<1 \cdot 0^{\mathrm{a}}\end{array}$ \\
\hline & 2 & $\begin{array}{l}09: 00 \\
15: 00\end{array}$ & $\begin{array}{l}13 \cdot 2 \pm 1 \cdot 1^{a} \\
11.6 \pm 1.9^{a}\end{array}$ & $\begin{array}{l}9 \cdot 0 \pm 1 \cdot 3^{\mathrm{b}} \\
7 \cdot 2 \pm 1 \cdot 5^{\mathrm{ab}}\end{array}$ & $\begin{array}{l}6.3 \pm 0.9^{b} \\
5.4 \pm 1.5^{b}\end{array}$ \\
\hline
\end{tabular}

Values are mean \pm s.e.m. for 8 hamsters/group.

Within rows, values with different superscript letters are significantly different $(P<0.05)$. 


\section{Luteal steroidogenesis (Table 6)}

In Group 1, significant quantities of progesterone were produced at 15:00 h on Day 1 and increased further by Day 2. In Groups 3 and 4 the production of progesterone by Day 1 CL was higher than in Group 1, although the initial concentrations in the CL (see Table 4) were significantly lower $(P<0.05)$. Production in Groups 3 and 4 was significantly increased on Day 2 compared with Day $1(P<0.05)$ but values were similar in all 3 groups. Oestradiol-17 $\beta$ was not produced by the CL in any of the groups on Days 1 or 2. For all groups, production rates of testosterone (Table 6) correlated well with the initial concentrations of the hormone (Table 4). Luteal testosterone production in Group 3 increased on Day $1(P<0.05)$, and values were higher on Day 1 than those in Group 4.

\section{Steroidogenesis in residual tissue (Table 7)}

On Day 1 there was a net loss of progesterone in Groups 1 and 3 although the tissue contained relatively high levels of progesterone at the time of incubation (see Table 5). In Groups 2 and 4 production rates of progesterone were very much greater on Days 1 and 2 aithough the tissue contained initially smaller amounts of the hormone. On Day 2, production rates of progesterone in Groups 1 and 3 were significantly increased from the values on Day $1(P<$ 0.05 ) although the initial concentrations of progesterone had decreased significantly in this time. The patterns of oestradiol-17 $\beta$ and testosterone production correlated with their initial concentrations (see Table 5). Values of oestradiol in Group 2 at 09:00 h on Day 1 were higher than those in this group at other times and in Groups 3 and 4. Small amounts of testosterone were produced on Days 1 and 2 in Groups 2 and 3 but values in Group 4 remained low.

Table 7. Progesterone, oestradiol-17\% and testosterone production rates of the residual ovarian tissue from hamsters after various treatments on Day 4 of the cycle

\begin{tabular}{|c|c|c|c|c|c|c|}
\hline Steroid & $\begin{array}{l}\text { Day } \\
\text { of the } \\
\text { cycle }\end{array}$ & $\begin{array}{l}\text { Time } \\
\text { (h) }\end{array}$ & $\begin{array}{c}\text { Group 1 } \\
\text { (sham-hypox.) }\end{array}$ & $\begin{array}{l}\text { Group } 3 \\
\text { (LH) }\end{array}$ & $\begin{array}{c}\text { Group } 4 \\
\text { (FSH) }\end{array}$ & $\begin{array}{l}\text { Group } 2 \\
\text { (saline) }\end{array}$ \\
\hline \multirow[t]{2}{*}{$\begin{array}{r}\text { Progesterone } \\
(\mathrm{ng} / \mathrm{mg} / \mathrm{h})\end{array}$} & 1 & $\begin{array}{l}09: 00 \\
15: 00\end{array}$ & $\begin{array}{l}-4 \cdot 4 \pm 0 \cdot 1^{\mathrm{a}} \\
-4 \cdot 7 \pm 0 \cdot 2^{\mathrm{a}}\end{array}$ & $\begin{array}{l}-1 \cdot 2 \pm 0.2^{b} \\
-1.0 \pm 0.3^{b}\end{array}$ & $\begin{array}{l}8 \cdot 1 \pm 1 \cdot 1^{c} \\
6 \cdot 9 \pm 1 \cdot 4^{c}\end{array}$ & $\begin{array}{l}6.6 \pm 0.7^{c} \\
5.4 \pm 1.0^{c}\end{array}$ \\
\hline & 2 & $\begin{array}{l}09: 00 \\
15: 00 \\
\end{array}$ & $\begin{array}{l}0.2 \pm 0.1^{a} \\
0.2 \pm 0.04^{a}\end{array}$ & $\begin{array}{l}1.2 \pm 0.3^{\mathrm{a}} \\
1.9 \pm 0.2^{\mathrm{a}} \\
\end{array}$ & $\begin{array}{l}7 \cdot 1 \pm 1 \cdot 4^{\mathrm{b}} \\
5 \cdot 3 \pm 1 \cdot 0^{\mathrm{b}}\end{array}$ & $\begin{array}{l}8 \cdot 3 \pm 1.8^{\mathrm{b}} \\
6 \cdot 7^{ \pm} \pm 1 \cdot 1^{\mathrm{b}} \\
\end{array}$ \\
\hline \multirow[t]{2}{*}{$\begin{array}{l}\text { Oestradiol } \\
\qquad(\mathrm{pg} / \mathrm{mg} / \mathrm{h})\end{array}$} & 1 & $\begin{array}{l}09: 00 \\
15: 00\end{array}$ & $\begin{array}{l}32 \cdot 5 \pm 5 \cdot 5^{a} \\
41 \cdot 6 \pm 7 \cdot 7^{\mathrm{a}}\end{array}$ & $\begin{array}{l}0 \cdot 8 \pm 0 \cdot 1^{\mathrm{b}} \\
0 \cdot 3 \pm 0 \cdot 1^{\mathrm{b}}\end{array}$ & $\begin{array}{l}3 \cdot 1 \pm 0.9^{b} \\
0.8 \pm 0.3^{b}\end{array}$ & $\begin{array}{l}7.8 \pm 1.3^{c} \\
0.9 \pm 0.1^{b}\end{array}$ \\
\hline & 2 & $\begin{array}{l}09: 00 \\
15: 00\end{array}$ & $\begin{array}{r}39 \cdot 8 \pm 6 \cdot 3^{\mathrm{a}} \\
124 \cdot 6 \pm 8 \cdot 9^{\mathrm{a}}\end{array}$ & $\begin{array}{l}<0 \cdot 2^{\mathrm{b}} \\
<0 \cdot 2^{\mathrm{b}}\end{array}$ & $\begin{array}{l}0.7 \pm 0 \cdot 1^{\mathrm{b}} \\
1.2 \pm 0.1^{\mathrm{b}}\end{array}$ & $\begin{array}{l}0.9 \pm 0.2^{\mathrm{b}} \\
1.6 \pm 0.3^{\mathrm{b}}\end{array}$ \\
\hline \multirow[t]{2}{*}{$\begin{array}{r}\text { Testosterone } \\
(\mathrm{pg} / \mathrm{mg} / \mathrm{h})\end{array}$} & 1 & $\begin{array}{l}09: 00 \\
15: 00\end{array}$ & $\begin{array}{c}<0 \cdot 2^{\mathrm{a}} \\
15 \cdot 2 \pm 3 \cdot 9^{\mathrm{a}}\end{array}$ & $\begin{array}{l}2 \cdot 5 \pm 0.4^{b} \\
2 \cdot 2 \pm 0 \cdot 3^{b}\end{array}$ & $\begin{array}{l}<0.2^{a} \\
<0.2^{c}\end{array}$ & $\begin{array}{l}3 \cdot 4 \pm 0.2^{c} \\
2 \cdot 2 \pm 0.3^{b}\end{array}$ \\
\hline & 2 & $\begin{array}{l}09: 00 \\
15: 00\end{array}$ & $\begin{array}{l}11.6 \pm 1.0^{\mathrm{a}} \\
11.7 \pm 1.4^{\mathrm{a}}\end{array}$ & $\begin{array}{l}1.8 \pm 0.4^{b} \\
1.5 \pm 0.2^{b}\end{array}$ & $\begin{array}{l}<0 \cdot 2^{\mathfrak{c}} \\
<0 \cdot 2^{\mathfrak{c}}\end{array}$ & $\begin{array}{l}3.0 \pm 0.4^{\mathrm{d}} \\
2.9 \pm 0.3^{\mathrm{b}}\end{array}$ \\
\hline
\end{tabular}

Values are mean \pm s.e.m. for 8 hamsters/group.

Within rows, values with different superscript letters are significantly different $(P<0 \cdot 05)$.

\section{Discussion}

In confirmation of a previous study (Greenwald, 1974), at 09:00 and 15:00 h on Day 1 serur levels of progesterone are significantly lower in FSH-treated than in LH-treated hypophy sectomized hamsters (Table 3), but are comparable in both groups at 09:00 and 15:00 h or Day 2. However, Greenwald (1974) found that the CL induced by FSH were associated with 
serum progesterone levels of about $3 \mathrm{ng} / \mathrm{ml}$ on Day 2 while the present value was $6 \mathrm{ng} / \mathrm{ml}$. We cannot account for this discrepancy. Progesterone production in vitro by CL on Days 1 and 2 did not differ for the LH- and FSH-treated hypophysectomized animals (Table 6). The CL induced by $\mathrm{LH}$ or $\mathrm{FSH}$ can therefore synthesize and release progesterone in vivo and in vitro in the absence of the pituitary. These data also indicate that, after ovulation, the continued presence of gonadotrophins is unnecessary for luteal synthesis and release of progesterone, at least for 2 days. After hypophysectomy on the morning of Day 1, hamster CL show the first morphological signs of regression on Day 3-the time of normal luteolysis (Greenwald, 1968). Thus, the life-span of the CL of the cycle is determined by the preovulatory surge of gonadotrophins.

The residual ovarian tissue after FSH treatment produces a large quantity of progesterone in vitro (Table 7), although the concentrations of the steroid before incubation are quite low (Table 5). In contrast, after injection of $\mathrm{LH}$, the tissue becomes depleted of progesterone in vitro on Day 1, although the concentration of progesterone before incubation is relatively high. This suggests that a major portion of the progesterone initially contained in the residual tissue of the LH-treated hypophysectomized hamster is converted to steroids other than those measured in the present study. These results also suggest that the steroidogenic capacity and enzyme systems related to steroidogenesis in the ovary may be different in hypophysectomized animals treated with LH or FSH.

The finding that the ovary of the saline-treated hypophysectomized hamster is still capable of producing in vitro large amounts of progesterone, but small amounts of oestradiol-17 $\beta$ and testosterone even at $48 \mathrm{~h}$ after deprivation of gonadotrophins is the subject of continuing investigations. Histochemically, preantral follicles lack lipids, cholesterol, steroid dehydrogenases and other enzymes related to steroidogenesis (Saidapur \& Greenwald, 1978a). The possibility therefore exists that the steroids are derived from interstitial tissue or atretic antral follicles that failed to ovulate.

The CL of the sham-hypophysectomized hamsters failed to show any in-vitro production of progesterone when incubated at 09:00 h Day 1 (Table 6), which agrees with our previous findings (Terranova et al., 1978). However, the CL are capable of secreting progesterone when incubated on the afternoon of Day 1 (Table 6). This potential for progesterone synthesis correlates with the development of the first ultrastructural signs of luteinization (S. K. Saidapur, C. Bill \& G.S. Greenwald, unpublished). The possible source of circulating levels of progesterone in the sham-operated hamster on the morning of Day 1 (Table 3) is evidently nonluteal in origin and presumably also does not represent an immediate contribution from the residual tissues (Table 7 ).

The $\mathrm{CL}$ of the sham-hypophysectomized hamsters contain appreciable amounts of oestradiol-17 $\beta$ and testosterone (Table 4), and oestradiol changes showed an apparent circadian pattern which was similar to that in serum. Testosterone levels in the residual tissue of the same animals showed similar circadian changes on the same days (Table 5). This suggests that testosterone, as a substrate for the $\mathrm{CL}$, may diffuse from the surrounding tissue which largely represents the interstitial tissue and antral follicles and that luteal oestradiol-17 $\beta$ is then synthesized de novo. The hamster CL, like the follicular granulosa cells, might have an efficient aromatizing enzyme system (Makris \& Ryan, 1975, 1977). In the presence of androstenedione or testosterone, the CL of the pregnant hamster produce large amounts of oestradiol-17 $\beta$ during incubation for $2 \mathrm{~h}$ (A. J. Vomachka \& G. S. Greenwald, unpublished). Furthermore, the presence of 17 $\beta$-hydroxysteroid dehydrogenase in hamster CL has been demonstrated histochemically (Saidapur \& Greenwald, 1978a). One cannot therefore exclude the possibility that some luteal secretion of oestradiol- $17 \beta$ occurs in vivo on Days 1 and 2 . The physiological significance of oestradiol- $17 \beta$ in the CL of the hamster is unknown but may be related to a luteotrophic action as shown in the rat (Takayama \& Greenwald, 1973; Gibori, Rodway \& Rothchild, 1977).

In general, the rise in circulating and ovarian oestrogen concentrations during the oestrous 
cycle correlates with the development of antral follicles (Greenwald, 1961; Shaikh, 1972; Baranczuk \& Greenwald, 1973; Saidapur \& Greenwald, 1978b). In the present study, there was an excellent correlation for oestradiol- $17 \beta$ and testosterone between the concentrations in the residual ovarian tissue and the in-vitro production rates on Days 1 and 2 (compare Tables 5 and 7). Antral follicles, in particular the granulosa cells, are the major sites of oestrogen synthesis in the hamster (Makris \& Ryan, 1975, 1977) and the low levels of oestradiol-17 $\beta$ in serum or residual tissue in the hamsters treated with saline, LH or FSH in the present study suggests that normal antral follicles are absent.

Concentrations of testosterone in serum, $\mathrm{CL}$ and residual tissue and production rates in vitro in the LH-treated hypophysectomized animals were higher than those in the FSH-treated hamsters on Days 1 and 2. Previous studies in the rat (Armstrong \& Papkoff, 1976; Katz \& Armstrong, 1976) have demonstrated that LH markedly increases testosterone production or decreases testosterone conversion by aromatase to oestrogen in the ovary. On the other hand, aromatization has been identified as a site of specific stimulation by FSH in ovarian granulosa cells in vivo and in vitro in the rat (Dorrington, Moon \& Armstrong, 1975; Moon, Dorrington \& Armstrong, 1975; Armstrong \& Papkoff, 1976; Erickson \& Hsueh, 1978). Since LH treatment results in histological evidence of stimulation of theca interna cells and interstitial cells in hypophysectomized rats (Greep, Van Dyke \& Chow, 1942; Lostroh \& Johnson, 1966) and since these cells contain LH receptors (Zeleznik, Midgley \& Reichert, 1974), it seems likely that in the present study these cells are responsible for the increased production of testosterone after LH treatment. The increased weight of residual tissue after LH treatment (Table 2) probably results from stimulation of the interstitial cells and theca interna cells.

In the present study, the CL induced by FSH on Day 1 produced large amounts of progesterone in vitro although serum progesterone levels were low. A similar situation exists for the ovaries of the saline-treated hypophysectomized hamster on Days 1 and 2. Further studies are needed to determine whether the inconsistency between the in-vitro and in-vivo levels of progesterone results from rapid conversion of the hormone in vivo into steroids other than those measured in this study.

K.T. was supported as a Ford Foundation fellow in reproductive biology. The research was supported by a grant from the National Institutes of Health (HD-00596). We thank the NIAMDD program of NIH for providing the ovine FSH and $\mathrm{LH}$.

\section{References}

Armstrong, D.T. \& Papkoff, H. (1976) Stimulation of aromatization of exogenous and endogenous and androgens in ovaries of hypophysectomized rats in vivo by follicle-stimulating hormone. Endocrinology 99, 1144-1151.

Baranczuk, R \& Greenwald, G.S. (1973) Peripheral levels of estrogen in the cyclic hamster. Endocrinology 92, 805-812.

Dorrington, J.H., Moon, Y.S. \& Armstrong, D.T. (1975) Estradiol-17 $\beta$ biosynthesis in cultured granulosa cells from hypophysectomized immature rat; stimulation by follicle stimulating hormone. Endocrinology 97 , $1328-1331$.

Erickson, G.F. \& Hsueh, A.I. (1978) Stimulation of aromatase activity by follicle stimulating hormone in rat granulosa cells in vivo and in vitro. Endocrinology 102, 1275-1282.

Exley, D., Johnson, M.W. \& Dean, P.D.G. (1971) Antisera highly specific for $17 \beta$-estradiol. Steroids $18,605-620$.
Gibori, G., Rodway, R. \& Rothchild, I. (1977) The luteotrophic effect of estrogen in the rat: prevention by estradiol of the luteolytic effect of an antiserum to luteinizing hormone in the pregnant rat. Endocrinology 101, 1683-1689.

Greenwald, G.S. (1961) Quantitative study of follicular development in the ovary of the intact or unilaterally ovariectomized hamster. J. Reprod. Fert. 2, 351-361.

Greenwald, G.S. (1967) Luteotropic complex of the hamster. Endocrinology 80, 118-130.

Greenwald, G.S. (1968) Failure of hypophysectomy to affect cyclic regression of hamster corpus luteum. $J$. Reprod. Fert. 16, 495-497.

Greenwald, G.S. (1971) Preovulatory changes in ovulating hormone in the cyclic hamster. Endocrinology 88, $671-677$.

Greenwald, G.S. (1974) Dissociation of ovulation and progesterone secretion following $\mathrm{LH}$ or FSH treatment of hypophysectomized pro-estrous hamsters. Endocrinology 95, 1282-1286. 
Greep, R.O. Van Dyke, H.B. \& Chow, B.F. (1942) Various biological effects of purified thylakentrin (FSH) and pure methakentrin (ICSH). Endocrinology 30, 635-649.

Katz, Y. \& Armstrong, D.T. (1976) Inhibition of ovarian estradiol- $17 \beta$ secretion by luteinizing hormone in prepubertal, pregnant mare's serum treated rats. Endocrinology 97, 1379-1385.

Lostroh, A.J. \& Johnson, R.E. (1966) Amounts of interstitial-cell-stimulating hormone and follicle stimulating hormone required for follicular development, uterine growth and ovulation in the hypophysectomized rat. Endocrinology 79, 991-996.

Makris, A. \& Ryan, K. (1975) Progesterone, androstenedione, testosterone, estrone and estradiol synthesis in hamster ovarian follicle cells. Endocrinology 96, 694-701.

Makris, A. \& Ryan, K. (1977) Aromatase activity of isolated hamster granulosa cells and theca. Steroids 29, 65-72.

Moon, Y.S. Dorrington, J.H. \& Armstrong, D.T. (1975) Stimulating action of follicle stimulating hormone on estradiol-17 $\beta$ secretion by hypophysectomized rat ovaries in organ culture. Endocrinology 97, 244247.

Pang, C.N. \& Johnson, D.C. (1974) A method for preparation of steroid-protein antigens for use in immunoassay of steroids. Steroids 23, 203-219.

Saidapur, S.K. \& Greenwald, G.S. (1978a) Sites of steroid synthesis in the ovary of the cyclic hamster: A histochemical study. Am. J. Anat. 151, 71-86.

Saidapur, S.K. \& Greenwald, G.S. (1978b) Peripheral blood and ovarian levels of sex steroids in the cyclic hamster. Biol. Reprod. 18, 401-408.

Shaikh, A.A. (1972) Estrone, estradiol, progesterone and $17 \alpha$-hydroxyprogesterone in the ovarian venous plasma during the estrous cycle of the hamster. Endocrinology 91, 1136-1140.

Snedecor, G.S. \& Cochrane, W.C. (1967) Statistical Methods. Iowa State University Press, Ames, Iowa.

Steel, R.G.D. \& Torrie, J.H. (1960) Principles and Procedures of Statistics. McGraw-Hill, New York.

Takayama, M. \& Greenwald, G.S. (1973) Direct luteotropic action of estrogen in the hypophysectomized-hysterectomized rat. Endocrincology 92, 1405-1413.

Surve, A.H., Barco, I., Brinckerhoff, J.H. \& Kirsch, S.J. (1976) Plasma levels of progesterone in pseudopregnant rabbits actively immunized with a progesterone-protein conjugate. Biol. Reprod. 15, 343349.

Terranova, P.F. \& Greenwald, G.S. (1978) Steroid and gonadotrophin levels during the luteal-follicular shift of the cyclic hamster. Biol. Reprod. 18, 170-175.

Terranova, P.F., Connor, J.S. \& Greenwald, G.S. (1978) In vitro steroidogenesis in corpora lutea and nonluteal ovarian tissues of the cyclic hamster. Biol. Reprod. 19, 249-255.

Umbreit, W.W., Burris, R.H. \& Stauffer, J.V. (1953) Manometric Techniques 3rd edn, pp. 132-133. Burgess Publishing Co., Minneapolis.

Yang, W.H. \& Papkoff, H. (1973) Effect of desialylation on ovulation-inducing activity of ovine interstitial cell-stimulating hormone, ovine follicle stimulating hormone, pregnant mare's serum gonadotropin and human chorionic gonadotropin in the hamster. Fert. Steril. 24, 633-639.

Zeleznik, A.J., Midgley, A.R., Jr \& Reichert, L.E., Jr (1974) Granulosa cell maturation in the rat: Increased binding of human chorionic gonadotropin following treatment with follicle-stimulating hormone in vivo. Endocrinology 95, 818-825. 